\title{
Article
}

\section{Habilitation provision for children and young people with vision impairment in the United Kingdom: A lack of clarity leading to inconsistencies}

Hogg, Kat, Thetford, Clare, Wheeler, Sara Louise, York, Sarah, Moxon, Rachel and Robinson, Jude

Available at http://clok.uclan.ac.uk/15893/

Hogg, Kat, Thetford, Clare ORCID: 0000-0003-2188-3052, Wheeler, Sara Louise, York, Sarah, Moxon, Rachel and Robinson, Jude (2017) Habilitation provision for children and young people with vision impairment in the United Kingdom: A lack of clarity leading to inconsistencies. British Journal of Visual Impairment, 35 (1). pp. 44-54. ISSN 0264-6196

It is advisable to refer to the publisher's version if you intend to cite from the work. http://dx.doi.org/10.1177/0264619616671975

For more information about UCLan's research in this area go to http://www.uclan.ac.uk/researchgroups/ and search for <name of research Group>.

For information about Research generally at UCLan please go to http://www.uclan.ac.uk/research/

All outputs in CLoK are protected by Intellectual Property Rights law, including Copyright law. Copyright, IPR and Moral Rights for the works on this site are retained by the individual authors and/or other copyright owners. Terms and conditions for use of this material are defined in the policies page. 
Habilitation provision for children and young people with vision impairment in the United Kingdom: A lack of clarity leading to inconsistencies

Kat Hogg, Guide Dogs, UK; Clare Thetford University of Liverpool, UK; Sara Louise Wheeler Bangor University, UK; Sarah York and Rachel Moxon Guide Dogs, UK; Jude Robinson University of Liverpool, UK

\begin{abstract}
The key to empowering and supporting children and young people (CYP) with vision impairment (VI) to achieve their potential lies in the delivery of habilitation training. Evidence has revealed that provision of habilitation services across the United Kingdom was inconsistent, with CYP with VI not receiving services in some areas. This research explored the accessibility and quality of habilitation provision for CYP with VI via two studies: (1) 12 qualitative case studies of habilitation practice and (2) surveys of habilitation training experiences, with CYP with $\mathrm{VI}(n=43)$ and with parents of CYP with VI $(n=68)$. Five themes were identified highlighting inconsistencies and variability in the delivery of habilitation training in recent years, a lack of focus on independent living skills training, on social inclusion and emotional well-being, a lack of support for parents and a lack of clarity with regard to the definition of habilitation, and who is responsible for providing training.
\end{abstract}

Keywords

Habilitation; independence; mobility; Quality Standards; social inclusion; vision impairment;

Introduction

In the United Kingdom, there are at least 41,000 children and young people (CYP) aged up to 25 years with vision impairment (VI) (Royal National Institute of Blind People [RNIB], 2013), affecting approximately $0.2 \%$ of CYP (Cumberland, Pathai, \& Rahi, 2010). In all, 20\% have additional special education needs and/or disabilities, while $30 \%$ have complex needs (RNIB, 2013).

While a sighted child typically develops independence skills by imitating what they observe (Cox \& Smitsman, 2006; Reimer, Cox, Boonstra, \& Smits-Engelsman, 2008; World Health Organization [WHO], 2007), children with impaired vision are unable to learn by example in the same way (Bigelow, 2003; Dale \& Sonksen 1998; Hindley, 2005). As a result, CYP with VI face significant challenges in all aspects of their development and learning (Dutton, 2011; Perez-Pereira \& Conti-Ramsden, 1999; Rahi and Cable, 2003). Previous research indicated that inclusion within mainstream schools did not necessarily give CYP with VI the same personal or social developmental opportunities as their sighted peers (Nzegwu \& Dooley, 2008). The key to empowerment and achievement of their maximum potential lies in the delivery of habilitation training and support services (Douglas, Pavey, McLinden, \& McCall, 2003; Pavey, Douglas, McCall, McLinden, \& Arter, 2002). Habilitation is 'the acquisition of mobility, orientation and other independent living skills in relation to CYP born with VI or who acquire it during childhood' (VISION 2020 UK, 2013). The Quality Standards in the Delivery of Habilitation Training (Quality Standards) provide a baseline for habilitation practice and outline the skills, knowledge, and understanding required to deliver habilitation training, as well as detailing what practitioners might be expected to deliver (Miller, Wall, \& Garner, 2011). The Quality Standards identify six learning outcomes for CYP with VI: (1) the maximum degree of independent living; (2) the maximum degree of travel and mobility; (3) emotional wellbeing, including self-confidence and self-esteem; (4) the maximum degree of social inclusion; (5) competence in the use of specialist habilitation tools as aids to mobility and independence; and (6) the ability to assess risk and anticipate likely areas of personal difficulty in mobility and independent living (Miller et al., 2011).

Provision of habilitation services across the United Kingdom has been reported as inconsistent, with CYP with VI in some areas not receiving services at all (Douglas et al., 2003; Kelleher, 2011; Pavey et al., 2002). The Guide Dogs Functionality of Needs Survey sampled young people with VI (age 11-22 years) and established that 70\% had received some mobility training, while $57 \%$ of parents reported that their child had received some kind of mobility training (Nzegwu \& Dooley, 2008). This programme of work aimed to explore the accessibility and quality of habilitation provision for CYP with VI in the United Kingdom, using both case studies of the current practice with users and habilitation officers and questionnaire surveys of the experiences of CYP with VI and parents of CYP with VI.

Methods

A mixed-method approach was used to explore the accessibility and quality of habilitation provision. Guide Dogs UK commissioned researchers at the University of Liverpool to carry out case studies of habilitation practice, 
benchmarked against the Quality Standards. In addition, Guide Dogs UK conducted two surveys, informed by the Quality Standards, investigating access to and experiences of habilitation provision and training. Ethical approval for the case studies was obtained from the University of Liverpool and for the surveys from the University of Nottingham. The results are presented separately for the case studies and the surveys, under the subheadings of the five themes identified. The discussion then considers findings from both studies.

Table 1. The population demographics for study participants in the 12 case studies and the survey of CYP with $\mathrm{VI}$ and parents of CYP with VI.

\begin{tabular}{|c|c|c|c|}
\hline \multirow{2}{*}{$\begin{array}{l}\text { Sample descriptor } \\
\text { CYP (N) }\end{array}$} & \multirow{2}{*}{$\begin{array}{l}\text { Case study participants } \\
12\end{array}$} & \multicolumn{2}{|c|}{ Survey participants } \\
\hline & & \multicolumn{2}{|l|}{43} \\
\hline & $<11$ years $=4$ & \multicolumn{2}{|c|}{$12-18$ years $=21$} \\
\hline & $\geq 11$ years $=8$ & \multicolumn{2}{|c|}{$19-25$ years $=22$} \\
\hline Parents (N) & 14 & \multicolumn{2}{|c|}{$\begin{array}{l}68 \text { ( } 65 \text { mothers, } 2 \text { fathers, and } 1 \\
\text { guardian) }\end{array}$} \\
\hline & & \multicolumn{2}{|c|}{$\mathrm{CYP} \leq 10$ years $=43$} \\
\hline & & \multicolumn{2}{|c|}{$C Y P \geq 11$ years $=25$} \\
\hline Mobility/habilitation officers (N) & 12 & \multicolumn{2}{|c|}{$\mathrm{N} / \mathrm{A}$} \\
\hline QTVI (N) & 12 & \multicolumn{2}{|l|}{$\mathrm{N} / \mathrm{A}$} \\
\hline \multicolumn{2}{|l|}{ Country of residence $(\mathrm{N})$} & CYP & Parents \\
\hline England & 6 & 41 & 64 \\
\hline Northern Ireland & 2 & 1 & 0 \\
\hline Scotland & 2 & 1 & 2 \\
\hline Wales & 2 & 0 & 2 \\
\hline \multicolumn{2}{|l|}{ Range of VI (\%) } & CYP & Parents \\
\hline Registered blind & 58.3 & 60 & 57 \\
\hline Registered partially sighed & 8.3 & 33 & 35 \\
\hline Not registered & 8.3 & 7 & 6 \\
\hline \multirow[t]{2}{*}{ Not sure/unknown } & 25.0 & 0 & 2 \\
\hline & & CYP & Parents \\
\hline Additional needs and/or disabilities (\%) & 50 & 50 & 51 \\
\hline Statement of Special Educational Needs & 41.7 (50 unknown) & 75 & 80 \\
\hline
\end{tabular}

(England only) (\%)

CYP: children and young people; N/A: not applicable; QTVI: Qualified Teacher of Children and Young People with Vision Impairment.

Case studies

Participants

A purposive approach to sampling was adopted, allowing the identification of the individuals best placed to address specific research questions (Flick, 2002). The maximum variation in the characteristics of CYP (Patton, 1990) was sought in order to allow for the exploration of as many different issues as possible. Participants were identified based on age, gender, nature of habilitation received, level and type of VI, type of school attended, and services accessed. CYP with complex needs were excluded as the Quality Standards are intended to be used by services for CYP without complex needs.

Case study procedure

Case studies were collected, through which a range of service user and professional perspectives were explored in detail. Each case study explored habilitation service provision in a single LA through the experience of one CYP with VI who was currently receiving habilitation training, plus at least one of their parents, their habilitation worker/mobility officer, and in most cases a Qualified Teacher of Children and Young People with Vision Impairment (QTVI). In all, 49 semi-structured interviews were carried out each lasting between 20 min and $2.5 \mathrm{hr}$. Young people aged over 11 years were given the choice of being interviewed alone or with a parent/service provider. Children aged under 11 years were able to participate in interviews with parents or service providers so long as they and their parents consented. Informed consent was obtained using information and consent materials produced for CYP with VI. Parental consent was also obtained for young people aged 1115 years who completed their own interviews. Data collection took place between December 2013 and April 2014.

Case study analysis 
Audio-recordings were transcribed and uploaded into NVivo software. Transcripts were analysed to identify text which informed the researchers' understanding of the issues surrounding habilitation services (Coffey \& Atkinson, 1996; Silverman, 2012). Summaries were produced for each case, highlighting key issues and themes. A coding scheme was developed around the key themes emerging across cases and the Quality Standards' learning outcomes. Each concept was then assigned a descriptive or analytical code, which were combined into conceptual categories and broader themes. This scheme was used to code the transcripts in NVivo.

Survey

Participants

Purposive sampling (Bryman, 2012) was used to recruit participants for two groups: CYP with VI aged between 12 and 25 years and parents of CYP with VI aged between 1 and 18 years. CYP who were 12 years and over were recruited and therefore likely to be able to articulate their habilitation experiences. Consultation with habilitation practitioners confirmed that all questions were suitable for CYP of this age. Young people aged 1925 years were also included to correspond with the ages in the Special Educational Needs (SEN) legislative framework. Parents of CYP aged 1-18 years were recruited to capture the habilitation experiences for parents of CYP of a range of ages. Blind Children UK's database of service users was used to identify potential participants. The average age of total CYP respondents was 18.4 years (age range, 13-25 years). The average age of CYP with VI whose parents responded was 9.1 years (age range, 2-18 years; Table 1).

Survey procedure

CYP with VI and parents of CYP with VI were invited, via a mail-out, to participate in an online survey (SNAP, www.snapsurveys.com). Separate surveys were created for CYP and for parents of CYP and took approximately $25 \mathrm{~min}$ to complete. Both surveys were broken down by CYP age group so that questions were appropriate for training and support likely to have been experienced at age-specific points in time. Multiple-choice closed questions were used to collect demographics, background information, and data on key aspects of habilitation provision. Open-ended questions were used to collect further background information and qualitative data on habilitation experiences. Informed consent was obtained from CYP and from parents of CYP under 18 years of age in England and under 16 years of age in Scotland. Data collection took place in September and October 2014.

Survey data analysis

The demographic characteristics of the CYP and parent samples are described below. Responses to multiplechoice questions were used to produce frequencies and percentages. Data obtained from open-ended questions were analysed to produce broad and inter-related themes. Direct quotes from open-ended questions are presented to support the findings.

Participant demographics. The demographic characteristics of the participants for the 12 case studies and the surveys of CYP with VI and parents of CYP with VI are shown in Table 1. For the case studies, six cases were from LAs where habilitation was provided by the LA directly; two services were provided by Guide Dogs, two by other voluntary organisations, and two provided through the LA supplemented by a Guide Dogs service. Eight cases were from urban areas and four from rural areas.

Results

Case studies

Variation and inconsistency in access to habilitation services. The 12 case studies revealed considerable variation in the accessibility of habilitation services. In some areas, service provision was very good according to service users and providers, while in others substantial shortcomings and gaps within the current provision were reported. When accessible and holistic habilitation services were available, service users reported positive benefits. However, while some families reported receiving services which they viewed as excellent, parents in several cases reported having to 'battle' for support for their children; several did so through the formal processes associated with the statement of SEN. However, for some parents, getting a statement proved too difficult to obtain, and for others, even where a statement was in place, this was no guarantee of receiving the habilitation they requested, or even what was agreed:

... To say it's in her statement means nothing to be quite honest. [child's name] is supposed to have two sessions a week and she's lucky if she gets one ... two years down the line, was still doing the same stuff ... (Parent of a 16-year old)

Furthermore, where high-quality habilitation services did reportedly exist, some CYP did not access them because there was no systematic provision of information and referral, particularly from medical services, even when CYP meet the criteria for certification and registration. The greatest gaps in provision appeared to lie within services for CYP post age 16 years, particularly if leaving education, and in provisions for supporting parents. The 
variation in service provision did not appear to be explained by devolved national legislation; instead, it appeared to reflect decision-making, funding, and service structures at LA level.

Less emphasis on independent living skills training than mobility training and variation in service provision. Mobility training was a priority for both service users and providers and dominated notions of what habilitation was. Where habilitation services were available, competence in CYP's mobility skills was generally perceived to be good. Where services were limited, this appeared to restrict the skills that CYP could develop. Some service users reported having ongoing battles to access mobility training and this lack of support was felt to limit the skills they were able to develop, as well as limiting their everyday lives. Independent living skills were addressed to a lesser degree than mobility training. Approaches to the provision of independent living skills training were variable.

Lack of support for social inclusion and even less focus on emotional well-being. Other learning objectives including social inclusion and emotional well-being were addressed less directly by service providers, and to varying degrees. The evidence also suggests that where a highly individualised approach was provided to support the emotional and social needs of CYP (and their families), it was perceived as highly beneficial. A 15-year-old girl was supported in delivering peer education about herself through presentations within the school. This was reported to have had a dramatically positive impact on her social integration at school:

... She's done a few talks last year. She went around the classes once a week and she took glasses and masks and things like that so they could all try out what visual impairment was like and she'd do a talk on her visual impairment and what could be done to help basically, and it seems to have, she's done really, really well because that's when the bullying started tailing off . . . (Parent of a 15-year old)

Parents are integral to the child's habilitation but are inadequately supported. Some services provided only limited training opportunities for independent living skills and placed greater responsibility upon parents for providing their children with these skills, without necessarily providing them with support to do so. Indeed, some parents indicated that they did not feel confident in supporting their children and required professional support and guidance which had not been accessible:

... When I am teaching him things like, I don't know chopping veg or whatever it might be, I don't know that my way is the right way for him, so it would be nice if we had you know somebody to come in and say right this is the right way to do it for [child's name] ... (Parent of a 13-year old)

What is habilitation and who is responsible for providing training? Evidence from the 12 service providers highlighted that budget cuts in recent years have impacted negatively on many services and are expected to have further impacts. Furthermore, there is a lack of clarity of exactly what habilitation is: whether it is a form of education or a social service. This confusion of exactly what it is and who is responsible for delivering its components was considered to underpin the problems of responsibilities for funding and delivery. For example, definitional issues surrounding habilitation meant that job or department roles often overlapped and debates surrounding responsibility for the delivery of specific components became the focus rather than the well-being of the CYP. A habilitation worker described a meeting at which a head teacher and a LA were debating who should pay for lunchtime staff to look after a child at lunchtime when he started school:

... As far as I know there are only two sources of money represented in this meeting; one is you and the other is you. So would you two just get out of the room right now, go and find somewhere where we can't hear you rowing and when you've agreed who's going to do it will you come back to the meeting. Because right at the moment mum is worried to death that nobody is going to look after him at lunchtime. So I don't want to hear another argument about lunchtime supervision because you both agree he should have it. So will you two just go and decide who is going to pick up the bill and then we carry on? ... (QTVI)

In some areas, there has been a historical dependency on voluntary organisations to provide support and services for CYP with VI.

Survey results

Variation and inconsistency in access to habilitation services. Parents reported that 25 (37\%) CYP with VI had never received mobility training, with 31 parents $(46 \%)$ reporting that their child had received mobility training during the previous year. A total of $39 \mathrm{CYP}(91 \%)$ reported that they had received mobility training at some point during their life and 24 (56\%) reported that they had received mobility training during the previous year. Even when a CYP with VI had received mobility training during the past year, the majority had not received a comprehensive service as per the Quality Standards: training tended not to cover the three key settings (home, school, and public environment) and was not received all year round; the parents' data revealed that 19 (28\%) CYP had received training during term time only. Training sessions often took place on a changeable or infrequent basis. In all, 11 (26\%) CYP respondents had mobility training once a week, 3 (7\%) twice a week, and 1 once a month, while $11(26 \%)$ had experienced ad hoc sessions, sometimes taking place on a weekly basis and other times fortnightly or monthly (the frequency of mobility training was unknown for 18 [42\%] CYP). A total 
of 36 (95\%) parents who reported that their child had received mobility training during the last year felt that their child would benefit from further training.

The data from parents indicated that the majority of CYP with VI had not received habilitation provision in line with the Quality Standards. When parents were asked about the process they went through to obtain support for their child in relation to their mobility, they reported (1) struggling to obtain habilitation support, (2) their CYP did not receive all or some of the habilitation support included in their statement of SEN, (3) CYP being trained by unskilled workers, (4) poor quality habilitation training, and (5) mobility training only being provided within the school setting:

... We are interested in habilitation training but haven't heard about it much as of yet even though it's written in our son's statement that he needs it ... (Parent of a 6-year old)

... My son initially got brilliant mobility support but when his teacher left it really went downhill. He has 1 hour a week in his statement but over the last year with his new teacher has had 4 sessions in 40 week. I have had to ring education up and really push to get the training. His mobility teacher had never been to his school until I insisted she went when he was having some difficulties. I feel I have had to beg for the training which he is entitled to ... (Parent of a 13-year old)

We received some mobility support from Social Services but this was only during holidays and for a limited duration ... (Parent of an 8-year old)

Over half $(n=14)$ of the CYP respondents who had received mobility training during the last year stated that there were some elements of mobility training that they would like to have learnt at an earlier age; these included crossing roads safely, using public transport, cane training, and general training that would have supported independence at an earlier age.

Less emphasis on independent living skills training than mobility training and variation in service provision. The evidence indicated that less emphasis is placed by some LAs on independent living skills training than on mobility training, with parents and academic teaching staff often taking on the responsibility for this training. In the 1218 age group, 10 (47\%) CYP aged 12-18 years had received training with learning to look after themselves, for example, developing skills such as cooking, organising their belongings, or clothes. Three of the 10 respondents stated that it would have been useful for them to have learnt certain daily living skills earlier in life, such as using a knife and fork. Six respondents stated that they thought that it would be useful for them to have further daily living skills training, such as help with cooking. Three parents reported that their child had not received any independent living skills training:

... I feel the service we have been provided is far from adequate and does not meet any of the aims set out in guidance for habilitation support. My child needs support with balance and crossing roads. She needs to use her other senses for orientation too. None of this has been provided despite my asking . . (Parent of a 7-year old) In the 19-25 age group, 16 of 22 (73\%) young people had received independent or daily living skills training though 11 (52\%) stated that they would like further training, most commonly in cooking and the use of kitchen appliances and equipment.

Lack of support for social inclusion and even less focus on emotional well-being. A total of 14 parents (21\%) were positive about both their child's academic attainment and social development, whereas 18 (26\%) parents reported that their child found it difficult to interact socially with their peers despite their positive academic performance. Five parents (7\%) expressed concerns about their child's ability to develop friendships, as well as reporting that their child was struggling academically. Only eight (12\%) parents reported that their child's classmates had received peer awareness training.

Parents are integral to the child's habilitation but are inadequately supported. A total of 11 parents (16\%) reported that they had received training to support their child with mobility. This support was provided by one QTVI, three VI units, five mobility officers, and two parents had attended Blind Children UK's 'Movement Matters' course. Four (20\%) CYP aged 12-18 years reported that their parents had attended some of their mobility training:

... Not much help and support is available to either the parent or affected child with a visual impairment. I feel isolated and upset as I don't know how best to support my child with her mobility needs . . . (Parent of a 3-year old)

... we have had zero independent living or social skill training. Everything our daughter can do in this field, we have taught her ourselves.... (Parent of a 15-year old)

What is habilitation and who is responsible for providing training? A total of 22 (32\%) parents stated that mobility training had been provided by education services, while 3 parents (4\%) each cited social services, charities/local voluntary groups, and schools. In all, 11 parents (16\%) had received training to support their child in developing 
mobility skills. Of 10 CYP aged 12-18 years who reported they had received daily living skills training, only 1 respondent was taught by a habilitation specialist, 7 were predominantly taught by their parents with some support from a teacher, and 2 were taught solely by their parents. In addition, it was reported that habilitation training had been received from staff that were unskilled:

... We had issues as our school QTVI was not mobility trained and therefore could only provide limited support at school. We received some mobility support from Social Services . . . the Social Services mobility officer had little experience of training children ... (Parent of an 8-year old)

Discussion

Both the case studies and surveys revealed considerable variation in the accessibility and quality of habilitation training across the United Kingdom. However, whether the case studies or the surveys are fully representative of the experiences of the national population of CYP is unclear. It is conceivable that both samples had some positive bias with better performing services more willing to participate. In addition, the two survey samples consisted of higher proportions of CYP registered as blind or partially sighted than in the population estimates of CYP with VI in England (VISION 2020 UK, 2015) and higher proportions of CYP with statements of SEN than those CYP who receive specialist educational support across LAs in England (Guide Dogs, 2012). The survey samples also consisted of higher proportions of CYP born with sight loss than in the epidemiological study reported by Rahi and Cable (2003). Therefore, it could be expected that the CYP who participated in this study would be known to, and supported by, their local vision support service. Nonetheless, both studies have illustrated that in some LAs, access to habilitation was not guaranteed even when CYP met the criteria for certification and registration, and/or were statemented and even if habilitation was included in a statement of SEN. It is plausible that the UK picture of habilitation provision for those CYP who are not registered or statemented may be bleaker still. Miller et al. (2011) regard VI as 'any level of visual impairment which has an effect on education, mobility and the ability to live independently'. If a functional definition of $V I$ was considered in relation to eligibility for habilitation training for CYP with VI, this would potentially include substantially more children than are currently certified as blind or partially sighted (Keil, 2013).

Both the case studies and the surveys found that parents were often left to provide their children with independent living skills training, without necessarily having been provided with the support to do so. The parent survey sample also reported that few parents had been provided with training to support their child's mobility training. These findings are concerning in light of a previous study where parents of CYP with VI reported that the need for improved mobility and the need for support for parents were important issues to consider to improve the situation for their children (Nzegwu \& Dooley, 2008). The findings of the studies reported here have revealed that not only is there still a need for improved mobility training for many CYP but also a substantial gap within habilitation provision for supporting parents.

Buultjens, Stead, and Dallas (2002) found that access to the curriculum for CYP with VI educated in mainstream schools often takes precedence to, and sometimes obscures, the issue of social inclusion. They suggest that despite the provision of resources (or lack of provision of resources) and parental involvement, CYP with VI have largely been left to make their own way socially. The case studies and survey data presented here add to this evidence; the findings indicate that in the mainstream school environment, CYP are not receiving direct support with their social development and this may reflect less focus on outcomes of social inclusion and emotional wellbeing than on academic progress and mobility and independent living skills training. Lewis and Collis (1997) cited in McAllister and Gray (2007) also suggested that there is less of an emphasis on social development than academic progress, arguing that this imbalance may be due to the difficulties that CYP with low vision have in negotiating the physical and social space within the school.

The importance of habilitation training for more holistic development of CYP with VI was raised by Wilson (2004), who argued that mobility training and the development of independent living skills can potentially enable a CYP to achieve social inclusion. Pavey et al. (2002) claimed that mobility and independence training could potentially enable a CYP to participate fully in all aspects of school life It could be argued that if a CYP and their family were provided with a habilitation service in line with the Quality Standards, a CYP with VI should potentially be able to participate fully in all aspects of school life. However, the results presented here indicate that there is insufficient emphasis placed on emotional well-being and social inclusion. It is feasible that VI services working in partnership with schools could work more effectively to assist CYP with social integration and that peer awareness training could form a key part of such support. This is highlighted by the case studies which reported on the improvements that interventions such as peer training could have on the lives of CYP with VI. In order to support a CYP achieve all of the six Quality Standards outcomes, a habilitation service should also provide support beyond the school environment and in the community and public environment. However, the case studies demonstrated that there are misunderstandings and debates within some LAs surrounding what habilitation is - whether it is a form of educational or social care provision, and thus who should fund and provide it. 


\section{Conclusion}

This study drew on case studies and survey material to explore the accessibility and quality of habilitation provision for CYP with VI in the United Kingdom, informed by the Quality Standards. There is considerable variation in the accessibility and quality of mobility training, with service provision being very good in some areas while in others it is wholly inadequate. Even where mobility training is provided, the service is predominantly not comprehensive, as per the Quality Standards. Less emphasis is placed on independent living skills training, with even less focus placed on the outcomes of social inclusion and emotional well-being, and support for parents is lacking. Access to habilitation was not guaranteed across LAs even when CYP met the criteria for certification and registration, and/or were statemented, even if habilitation was included in their statement of SEN. These findings indicate that there is a need for improvement in the provision of habilitation training to CYP with $\mathrm{VI}$, and in particular the need for greater clarity with regard to the definition of habilitation, which may help address inconsistencies in the current provision. Moreover, the findings identify a need for further research into the nature of habilitation training and how this should be delivered and mapped according to individual need. 